\title{
Father hands it down: patrilineal inheritance of chloroplast DNA in conifers may help to uncover relations of reproduction, population biology and longevity of trees
}

\author{
Ulrich Lüttge ${ }^{1}$
}

Published online: 3 February 2016

(c) Springer-Verlag Berlin Heidelberg 2016

Organelles such as the mitochondria and plastids contain their own DNA, and with their transfer across generations there is organelle-bound inheritance. Mitochondrial inheritance in recent times has increasingly been regarded as a focus of general interest. Such interest includes the public media, because it can be used in studies of molecular phylogenetics of mammals and especially our own lineage of the genus Homo. Various theories of phylogeny and of global human migrations, with their time scales given by the molecular clock, can be investigated thanks to the uniqueness of mitochondrial DNA (mtDNA) inheritance mechanisms. Mitochondrial inheritance in mammals is matrilinear, i.e., mtDNA is only derived from the mother. The female egg contains many mitochondria, while the male sperm has only a few, which are destroyed in fecundation when the sperm merges with an egg.

For studying molecular phylogenetics and molecular systematics, mtDNA has a number of advantages over nuclear DNA (ncDNA) (Cann et al. 1987): (1) it is easier to extract; (2) there are many copies in each cell; (3) mutations accumulate several times faster in mtDNA than in ncDNA, so that dynamics can be better documented; (4) there is no recombination of mtDNA between generations, so that individuals can be related to one another, which is important in population biology; and (5) if uniparental as in mammals, it allows direct genetic tracing of lines.

Mammals, of course, do not have plastids, but in plants there is organelle-related inheritance via both mitochondria and chloroplasts. There is uniparental inheritance, which

Ulrich Lüttge

luettge@bio.tu-darmstadt.de

1 Department of Biology, Technical University of Darmstadt, Schnittspahnstrasse 3-5, 64287 Darmstadt, Germany may be not only matrilinear but also patrilinear, and both may be combined in biparental inheritance. As in animals, the patrilinear inheritance is rare case because organelles come mainly from the egg cells (Kadereit et al. 2014). Thus, patrilinear inheritance via plastid DNA (plDNA) among some plant lineages, particularly in the conifers, is a case of special interest. This is described in the review on "Archegonium and fertilization in Coniferopsida" by Zhang and Zheng (2016) in this issue of Trees: Structure and Function. The authors review the structure of the female gametophyte of conifers. They also summarize the molecular evidence available on the genetic regulation of development of the female apparatus for fertilization. However, knowledge is still very limited.

This is particularly challenging in view of the implications of patrilinear plDNA inheritance. What happens to maternal plDNA in the conifers? In the egg cells of developing archegonia, plastids are degraded to produce proteid vacuoles, which are cellular bodies formed in the egg cells. Proteid vacuoles accumulate protein and are likely to serve as nutrition for fertilization and early proembryo development. When the egg cell has reached maturity, the remaining maternal plastids are degraded. Thus, the fertilized egg cells lack maternal plastids, so that plastids in the embryo are exclusively derived from the pollen giving the patrilinear plDNA inheritance.

These observations offer new approaches for the study of conifers. In analogy to mtDNA, plDNA may have similar advantages for molecular phylogeny and molecular systematics. Beyond the analogies with matrilinear inheritance of mtDNA in mammals mentioned above, the peculiarities of the Coniferopsida may help to uncover interesting features of trees. In the patrilinear inheritance it is not the mother, but the father who hands down inheritance. We may learn more about the roles of dioecy and 
monoecy, as in the Coniferopsida we find lineages which are dioecious and monoecious, respectively. In the family Pinaceae all species are monoecious, i.e., female and male gametes develop on the same plants. Studies of patrilinear inheritance may reveal relations of population biology and plant age with respect to the longevity of trees, where, for example, even thousands of years old specimen of Pinus longaeva D.K. Bailey (syn. Pinus aristata var. longaeva [D.K.Bailey] Little) are still fertile, with almost 5000 years old individuals being the oldest still living organisms on Earth.

\section{References}

Cann RL, Stoneking M, Wilson AC (1987) Mitochondrial DNA and human evolution Nature 325:31-36

Kadereit JW, Körner C, Kost B, Sonnewald U (2014) Strasburger. Lehrbuch der Pflanzenwissenschaften. Springer Spektrum, Berlin Heidelberg

Zhang M, Zheng C-X (2016) Archegonium and fertilization in Coniferopsida. Trees 30(1). doi:10.1007/s00468-015-1349-2 